\title{
Vibrational Spectroscopy of Chemical Species in Silicon and Silicon-Rich Nitride Thin Films
}

\author{
Kirill O. Bugaev, ${ }^{1,2}$ Anastasia A. Zelenina, ${ }^{1,2}$ and Vladimir A. Volodin ${ }^{1,2}$ \\ ${ }^{1}$ A.V. Rzhanov Institute of Semiconductor Physics, Russian Academy of Sciences, Lavrentieva Avenue 13, Novosibirsk 630090, Russia \\ ${ }^{2}$ Physical Faculty, Novosibirsk State University, Pirogova Street 2, Novosibirsk 630090, Russia
}

Correspondence should be addressed to Vladimir A. Volodin, volodin@isp.nsc.ru

Received 24 March 2011; Revised 6 June 2011; Accepted 20 June 2011

Academic Editor: Alexander Milekhin

Copyright ( $) 2012$ Kirill O. Bugaev et al. This is an open access article distributed under the Creative Commons Attribution License, which permits unrestricted use, distribution, and reproduction in any medium, provided the original work is properly cited.

\begin{abstract}
Vibrational properties of hydrogenated silicon-rich nitride $\left(\mathrm{SiN}_{x}: \mathrm{H}\right)$ of various stoichiometry $(0.6 \leq x \leq 1.3)$ and hydrogenated amorphous silicon (a-Si:H) films were studied using Raman spectroscopy and Fourier transform infrared spectroscopy. Furnace annealing during 5 hours in $\mathrm{Ar}$ ambient at $1130^{\circ} \mathrm{C}$ and pulse laser annealing were applied to modify the structure of films. Surprisingly, after annealing with such high-thermal budget, according to the FTIR data, the nearly stoichiometric silicon nitride film contains hydrogen in the form of $\mathrm{Si}-\mathrm{H}$ bonds. From analysis of the FTIR data of the Si-N bond vibrations, one can conclude that silicon nitride is partly crystallized. According to the Raman data a-Si:H films with hydrogen concentration $15 \%$ and lower contain mainly $\mathrm{Si}-\mathrm{H}$ chemical species, and films with hydrogen concentration $30-35 \%$ contain mainly $\mathrm{Si}-\mathrm{H}_{2}$ chemical species. Nanosecond pulse laser treatments lead to crystallization of the films and its dehydrogenization.
\end{abstract}

\section{Introduction}

The interest in amorphous, nano- and microcrystalline silicon films on nonrefractory inexpensive substrates and their crystallization is stimulated by demands of giant microelectronics. For example, the enlargement of sizes of flatpanel displays with active thin film transistor matrix can be described as "reverse Moor's law." Scientific interest in the silicon-rich nitride (SRN) films is growing due to their perspectives for application. The most important applications of SRN films are silicon-based optoelectronic devices [1], nonvolatile memory (flash-memory) devices [2], and new tandem solar cells based on silicon and silicon oxide (silicon nitride) heterostructures [3]. Silicon nanoclusters and SRN films can be applied in novel quantum-dots-based solar cells with enhanced efficiency [4].

Modern plasma-enhanced chemical vapor deposition (PECVD) technique allows the production of amorphous silicon films and SRN films with temperature of substrate lower than $100^{\circ} \mathrm{C}$ [5]. As reagents containing hydrogen are mainly used in PECVD, as-deposited films are hydrogenated. Hydrogen plays important role in electrical and optical properties of the films and also has influence on stability of the films. So, it is important to develop express, nondestructive spectroscopic approaches for studies of hydrogen in amorphous hydrogenated silicon (a-Si:H) films and hydrogenated SRN films. The present paper is devoted to studies of as-deposited films as well as furnace- and pulselaser-treated films with the use of Raman spectroscopy and Fourier Transform Infrared (FTIR) spectroscopy.

\section{Experiment Details}

Hydrogenated SRN films $\left(\mathrm{SiN}_{x}: \mathrm{H}\right)$ of different stoichiometry were deposited on the $\mathrm{Si}(100)$ substrates with the use of lowfrequency PECVD method. The frequency of discharge was $55 \mathrm{kHz}$, and the films were deposited from the gas mixture of ammonia $\left(\mathrm{NH}_{3}\right)$ and monosilane $\left(\mathrm{SiH}_{4}\right)$. The stoichiometry parameter $x$ depends on the ratio of ammonia/monosilane flows. The growth technology is described elsewhere in more details [6]. All SRN films were deposited at substrate temperature $100^{\circ} \mathrm{C}$, the reactor pressure during deposition was $150 \mathrm{~Pa}$, the deposition time was 16 minutes, and the plasma power was $400 \mathrm{~W}$. Parameters of the films are shown in Table 1.

Amorphous silicon films were deposited on glass substrates using two methods. The first method is evaporation 
TABLE 1: Growth parameters, thickness, and composition of hydrogenated SRN films.

\begin{tabular}{lcccc}
\hline $\begin{array}{l}\text { Number } \\
\text { of } \\
\text { samples }\end{array}$ & $\begin{array}{c}\text { Flow ratio } \\
\mathrm{NH}_{3} / \mathrm{SiH}_{4}\end{array}$ & $\begin{array}{c}\text { Thickness, } \\
\mathrm{nm}\end{array}$ & $\begin{array}{c}\text { Growth } \\
\text { temperature, } \\
{ }^{\circ} \mathrm{C}\end{array}$ & $\begin{array}{c}\text { Stoichiometric } \\
\text { parameter } x\end{array}$ \\
\hline 611 & 5 & 240 & 100 & 1.3 \\
613 & 1.5 & 400 & 100 & 0.95 \\
615 & 0.5 & 450 & 100 & 0.6 \\
\hline
\end{tabular}

TABLE 2: Growth parameters, thickness, and hydrogen concentration of amorphous silicon films.

\begin{tabular}{lccc}
\hline $\begin{array}{l}\text { Number } \\
\text { of samples }\end{array}$ & $\begin{array}{c}\text { Thickness, } \\
\mathrm{nm}\end{array}$ & $\begin{array}{c}\text { Growth } \\
\text { temperature, }{ }^{\circ} \mathrm{C}\end{array}$ & $\begin{array}{c}\text { Hydrogen concentration, } \\
\text { atomic per cents }\end{array}$ \\
\hline 1 & 100 & 20 & 0 \\
2 & 90 & 280 & 10 \\
3 & 110 & 225 & 15 \\
4 & 75 & 200 & $30-35$ \\
\hline
\end{tabular}

of monocrystalline silicon target by electron beam in high vacuum and deposition onto unheated substrate. The films deposited by this method do not contain hydrogen. The second method is PECVD at various temperatures using different PECVD reactors. The parameters of the films are shown in Table 2. It is known that optical gap of a-Si:H depends on hydrogen concentration [7]. According to optical gap measurements from light transmission and reflection data, the films grown at temperature $280^{\circ} \mathrm{C}$ contain $\approx 10$ atomic $\%$ of hydrogen (optical gap $\approx 1.4 \mathrm{eV}$ ); the films grown at temperature $225^{\circ} \mathrm{C}$ contain $\approx 15 \%$ of hydrogen (optical gap $\approx 1.6 \mathrm{eV}$ ); the films grown at temperature $200^{\circ} \mathrm{C}$ contain $30-35 \%$ of hydrogen (optical gap $\approx 2 \mathrm{eV}$ ).

Laser ellipsometry $(\lambda=632.8 \mathrm{~nm})$ was applied to measure the thickness of the films. To study the states of hydrogen and vibration of the Si-N bonds, the FTIR spectroscopy was applied. The FTIR spectrometer FT-801, produced by scientific enterprise "SIMEX" (Novosibirsk, Russia), was used. The spectral range of the spectrometer is from 550 to $5500 \mathrm{~cm}^{-1}$, and the spectral resolution can be optionally changed from 4 to $0.5 \mathrm{~cm}^{-1}$. The structural properties of as-deposited and annealed films were studied using Raman spectroscopy technique. All Raman spectra were recorded in the back-scattering geometry. The $514.5 \mathrm{~nm}$ $\mathrm{Ar}^{+}$laser line was used as a light source. Triple spectrometer T64000 (Horiba Jobin Yvon) with micro-Raman setup and liquid-nitrogen-cooled CCD matrix detector was used. The spectral resolution was not worse than $1 \mathrm{~cm}^{-1}$. All spectra were measured at room temperature. To avoid heating of the films, the laser beam was slightly defocused; the spot diameter was equal to about $4-6 \mu \mathrm{m}$; the laser power reaching the sample was within $2-3 \mathrm{~mW}$. The spectra were registered in the $Z(X X) \bar{Z}$ polarization geometry. Furnace annealing of the samples in $\mathrm{Ar}$ ambient for 5 hours at temperature $1130^{\circ} \mathrm{C}$ was performed at the Institute of Electron Technology (Warsaw, Poland). The triple harmonic of YAG:Nd laser

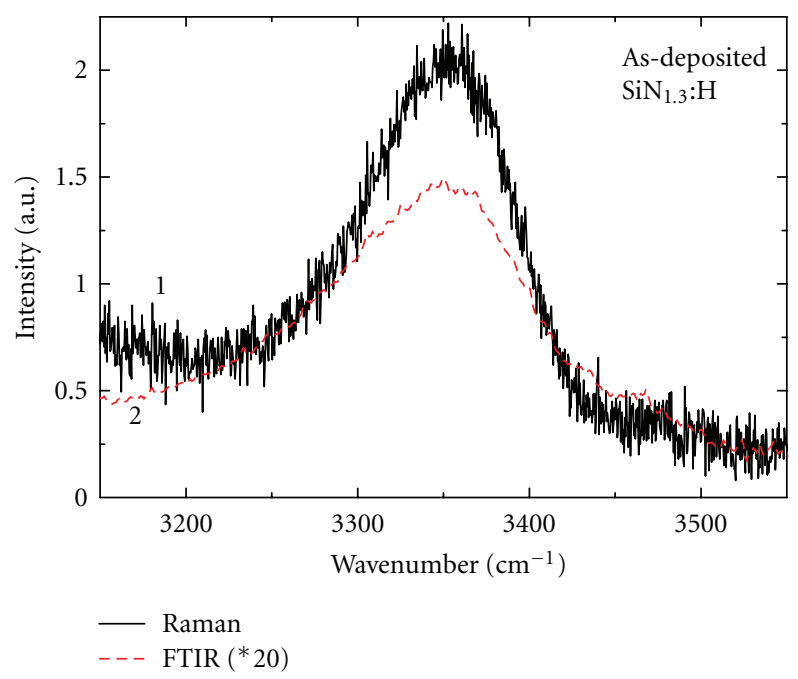

Figure 1: Raman and FTIR spectra of $\mathrm{SiN}_{1.3}: \mathrm{H}$ film in frequency range of valence vibration of $\mathrm{N}-\mathrm{H}$ bonds.

$(\lambda=335 \mathrm{~nm}$, pulse duration of $10 \mathrm{~ns})$ was used for laser treatments of the as-deposited films.

\section{Results and Discussion}

In Figure 1 one can see Raman spectroscopy and FTIR data concerning $\mathrm{N}-\mathrm{H}$ valence (stretching) vibrations in sample 611 (stoichiometry is estimated as $\mathrm{SiN}_{1.3}: \mathrm{H}$ ). For convenience, the FTIR data was multiplied by 20 times. According to both Raman data and FTIR data, the position of $\mathrm{N}-\mathrm{H}$ valence vibration peak is $3350 \mathrm{~cm}^{-1}$. An advantage of Raman spectroscopy method is the possibility to use substrates that are not transparent in IR region. When the substrate is not transparent, only reflection setup can be used. Using multiple internal transmission, the sensitivity of IR spectroscopy can be notably improved [8]. Figure 2 shows shift of the position of $\mathrm{N}-\mathrm{H}$ valence vibration peak versus $\mathrm{NH}_{3}$ to $\mathrm{SiH}_{4}$ ratio during deposition of $\mathrm{SiN}_{x}: \mathrm{H}$ films. With changing of stoichiometry parameter $x$ (1.3, 0.95 , and 0.6$)$ the frequency also changes $(3350,3342$, and $3335 \mathrm{~cm}^{-1}$ ) accordingly. The frequency of Si-H valence vibrations changes from 2170 to $2100 \mathrm{~cm}^{-1}$ with decrease of stoichiometry parameter $x$ from 1.3 to 0.6 [6]. This is because of influence of neighboring atoms on frequencies of valence modes of $\mathrm{Si}-\mathrm{H}$ and $\mathrm{N}-\mathrm{H}$ bonds. It should be noted that Ali with coworkers [9] have also observed the shift of the position of $\mathrm{N}-\mathrm{H}$ valence vibration peak versus stoichiometry of $\mathrm{SiN}_{x}: \mathrm{H}$ films.

In Figure 3 one can see Raman spectroscopy and FTIR data concerning $\mathrm{Si}-\mathrm{H}$ valence vibrations for $\mathrm{SiN}_{1.3}: \mathrm{H}$ film. According to the FTIR data the position of $\mathrm{Si}-\mathrm{H}$ valence vibration peak is $2170 \mathrm{~cm}^{-1}$, but according to the Raman spectroscopy data the position of peak is $2187 \mathrm{~cm}^{-1}$. A mercury lamp was used for back lighting of LCD monitor of experimental setup, and parasitic light can reach input slit of spectrometer. So, one can see in the Raman spectra a doublet (leakage from mercury lamp). One can see also a peak 


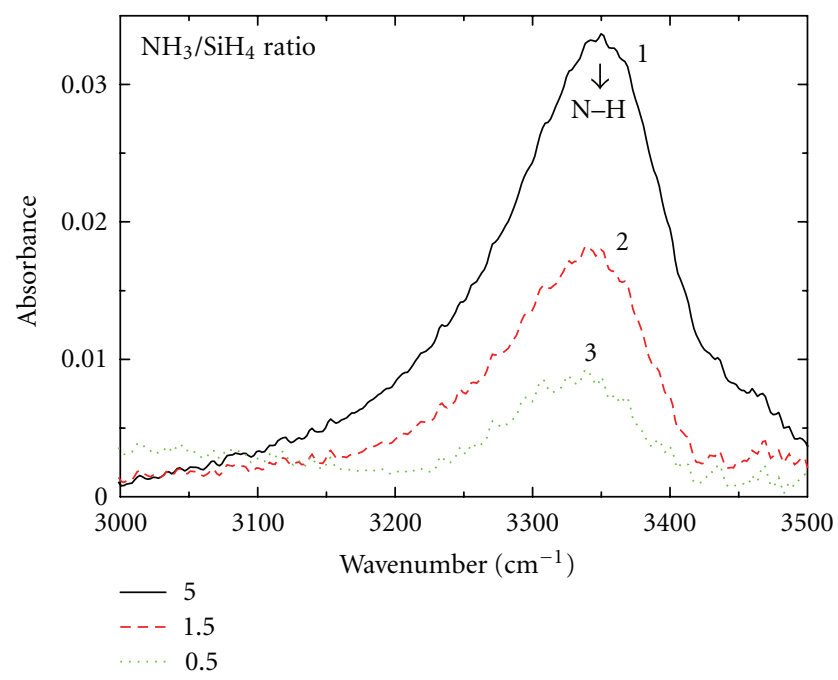

FIGURE 2: FTIR spectra of as-deposited SRN films in frequency range of valence vibration of $\mathrm{N}-\mathrm{H}$ bonds.

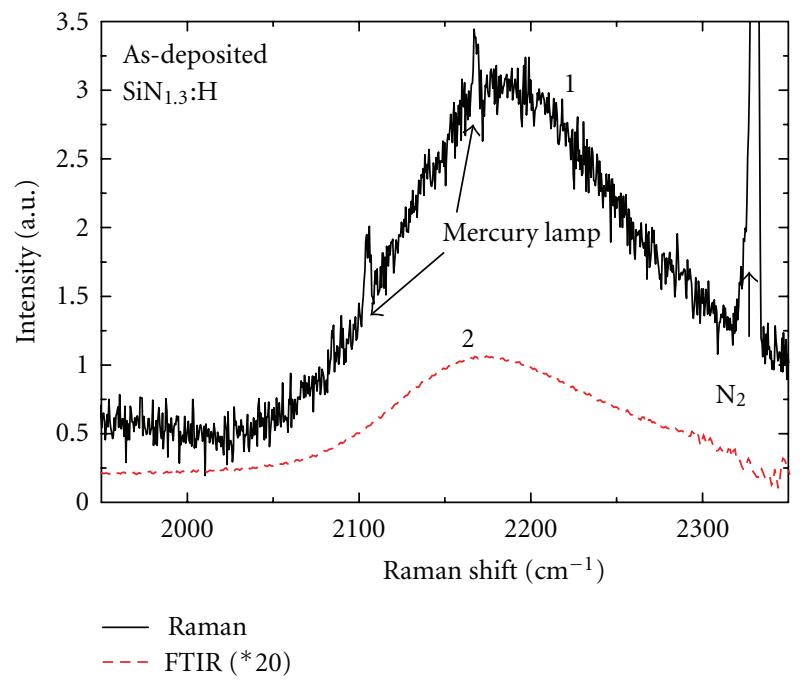

FIgURE 3: Raman and FTIR spectra of $\mathrm{SiN}_{1.3}: \mathrm{H}$ film in frequency range of valence vibration of $\mathrm{Si}-\mathrm{H}$ bonds.

due to Raman scattering on $\mathrm{N}_{2}$ molecules in atmosphere. Both Raman and FTIR peaks are asymmetric, so one can assume presence of $\mathrm{Si}-\mathrm{H}$ and $\mathrm{SiH}_{2}$ bonds in this film. From fitting of FTIR spectrum by two Gaussians one can assume that frequency of $\mathrm{Si}-\mathrm{H}$ valence vibration is $2170 \mathrm{~cm}^{-1}$ and frequency of $\mathrm{Si}-\mathrm{H}_{2}$ valence vibration is $2260 \mathrm{~cm}^{-1}$. The difference in positions of the Raman scattering and the FTIR peaks may be due to different contribution of $\mathrm{Si}-\mathrm{H}$ and $\mathrm{SiH}_{2}$ bond valence vibration in dipole moment and polarisability.

Knowing the thickness of a film and effective absorption cross-sections for $\mathrm{Si}-\mathrm{N}, \mathrm{Si}-\mathrm{H}$, and $\mathrm{N}-\mathrm{H}$ bonds, one can calculate the concentration of chemical bonds. The effective absorption cross-section $S_{\text {eff }}$ for valence vibration of Si-N bonds is $1.6 \cdot 10^{-19} \mathrm{~cm}^{2}[10]$, and $S_{\text {eff }}$ for valence vibration of $\mathrm{Si}-\mathrm{H}$ bonds is $0.57 \cdot 10^{-19} \mathrm{~cm}^{2}$ [11]. According to different

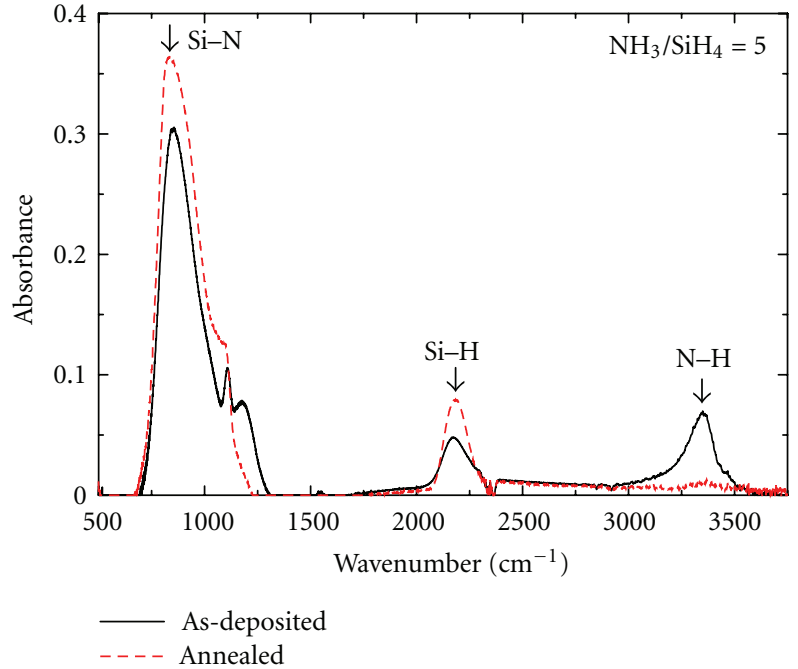

FIGURE 4: FTIR spectra of as-deposited and furnace-annealed $\mathrm{SiN}_{1.3}: \mathrm{H}$ film.

data, $S_{\text {eff }}$ for valence vibration of $\mathrm{N}-\mathrm{H}$ bonds is 0.48 . $10^{-19} \mathrm{~cm}^{2}$ [11] or $0.8 \cdot 10^{-19} \mathrm{~cm}^{2}$ [12]. Concentration of chemical species can be calculated as $\mathrm{N}\left(\mathrm{cm}^{-3}\right)=A /(d(\mathrm{~cm})$. $\left.S_{\text {eff }}\left(\mathrm{cm}^{2}\right)\right)$, where $A$ is the height of absorbance peak (dimensionless parameter) and $d$ is thickness. The results are shown in Table 3. The concentration of N-H species is calculated using $S_{\text {eff }}$ according to Lanford [11] and Stein [12]. It should be noted that Stein and Wegener [12] have used multiple internal transmissions but Lanford and Rand [11] used normal transmission geometry. We also have used normal transmission geometry. So, the $S_{\text {eff }}$ obtained by Lanford is more preferable for analysis of our data. From Table 3 one can see that total concentration of $\mathrm{Si}-\mathrm{N}, \mathrm{Si}-\mathrm{H}$, and $\mathrm{N}-\mathrm{H}$ bonds decreases with decreasing of stoichiometry parameter $x$. This is because vibrations of Si-Si bonds do not change dipole momentum and are not active in FTIR. But they are active in Raman scattering. And Raman signal from amorphous silicon clusters was detected for sample number 615 [6]. The total concentration of Si-N bonds in stoichiometric $\mathrm{Si}_{3} \mathrm{~N}_{4}$ is about $15.5 \cdot 10^{22} \mathrm{~cm}^{-3}$ [13]. So, one can assume that annealed near stoichiometric sample number 611 (Table 3) contains not only $\mathrm{Si}-\mathrm{N}$ and $\mathrm{Si}-\mathrm{H}$ bonds but also some concentration of Si-Si bonds. But concentration of such bonds is not high enough to be detected by Raman spectroscopy.

The FTIR spectra of as-deposited and annealed $\mathrm{SiN}_{1.3}: \mathrm{H}$ films are shown in Figure 4 in range from 500 to $3900 \mathrm{~cm}^{-1}$. Surprisingly, this nearly stoichiometric silicon nitride film still contains hydrogen after annealing with high-thermal budget, mainly in the form of the $\mathrm{Si}-\mathrm{H}$ bonds. In this film, the peak, corresponding to absorption on stretching vibrations of the $\mathrm{Si}-\mathrm{H}$ bonds, becomes even higher. The peak at $1175 \mathrm{~cm}^{-1}$ in spectrum of as-deposited film can be related to absorbance by bending vibrations of the $\mathrm{N}-\mathrm{H}$ bonds [14] Peculiarities at $850-900 \mathrm{~cm}^{-1}$ in spectrum of annealed film can be related to absorbance by stretching vibrations of the $\mathrm{Si}-\mathrm{N}$ bonds in the $\alpha$-modification of crystalline silicon 
TABLE 3: Concentration of chemical species in SRN films according to FTIR data.

\begin{tabular}{lcccc}
\hline Number of samples & $\begin{array}{c}\mathrm{Si}-\mathrm{N} \\
10^{22} \mathrm{~cm}^{-3}\end{array}$ & $\begin{array}{c}\mathrm{Si}-\mathrm{H} \\
10^{22} \mathrm{~cm}^{-3}\end{array}$ & $\begin{array}{l}\mathrm{N}-\mathrm{H} \text { (for } S_{\text {eff according }} \\
\text { to Lanford) } 10^{22} \mathrm{~cm}^{-3}\end{array}$ & $\begin{array}{l}\mathrm{N}-\mathrm{H} \text { (for } S_{\text {eff }} \text { according } \\
\text { to Stein) } 10^{22} \mathrm{~cm}^{-3}\end{array}$ \\
\hline 611 & 8 & 3.2 & 5 & 3 \\
611 annealed & 10.5 & 6 & bellow 0.1 & bellow 0.06 \\
613 & 5.58 & 3.64 & 0.9 & 0.54 \\
615 & 3.75 & 2.92 & 0.32 & 0.19 \\
\hline
\end{tabular}

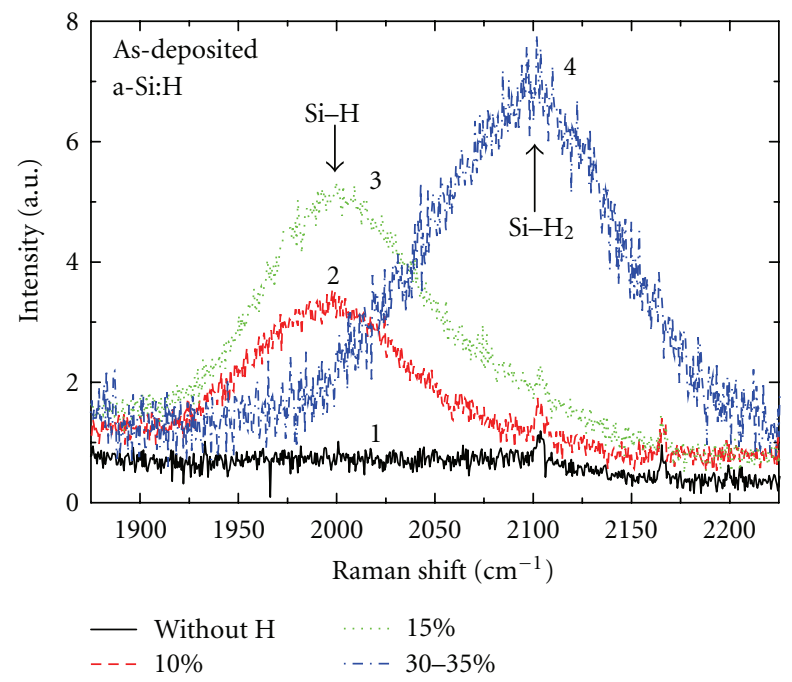

FIGURE 5: Raman spectra of a-Si:H films in frequency range of valence vibration of $\mathrm{Si}-\mathrm{H}$ bonds.

nitride $[15,16]$. Maybe partial crystallization of silicon nitride retards the dehydrogenization of the film. It has been detected earlier [17] that the closer is the stoichiometry parameter of the SRN films to that of stoichiometric $\mathrm{Si}_{3} \mathrm{~N}_{4}$, the higher temperature is needed for effusion of hydrogen (dehydrogenization) from these films. However, short-time annealing at temperature $850^{\circ} \mathrm{C} \mathrm{[17]} \mathrm{and} \mathrm{annealing} \mathrm{at} 800^{\circ} \mathrm{C}$ for 2 hours [18] lead to total dehydrogenization of the SRN films, with the stoichiometry parameter $x$ below 1 . So, as it was abovementioned, one can assume that, for the case of nearly stoichiometric silicon nitride film, furnace annealing leads to so-called hardening of silicon nitride inhibiting hydrogen outdiffusion.

Figure 5 shows Raman spectra of amorphous silicon films with different hydrogen concentrations. All films were deposited on glass substrates that are not transparent in IR region, so it was impossible to analyze them using FTIR in normal geometry. One can see peaks due to scattering on valence vibrations of $\mathrm{Si}-\mathrm{H}$ bonds. In Raman spectrum of the only film deposited in vacuum (without hydrogen) this peak is absent. As one can see from Raman spectra, film deposited at temperature $200^{\circ} \mathrm{C}$ contains mostly Si$\mathrm{H}_{2}$ bonds, because the position of $\mathrm{Si}-\mathrm{H}_{2}$ peak is about $2100 \mathrm{~cm}^{-1}$. The frequency of $\mathrm{Si}-\mathrm{H}$ peak is about $2000 \mathrm{~cm}^{-1}$ [19]. The films deposited at temperatures higher than

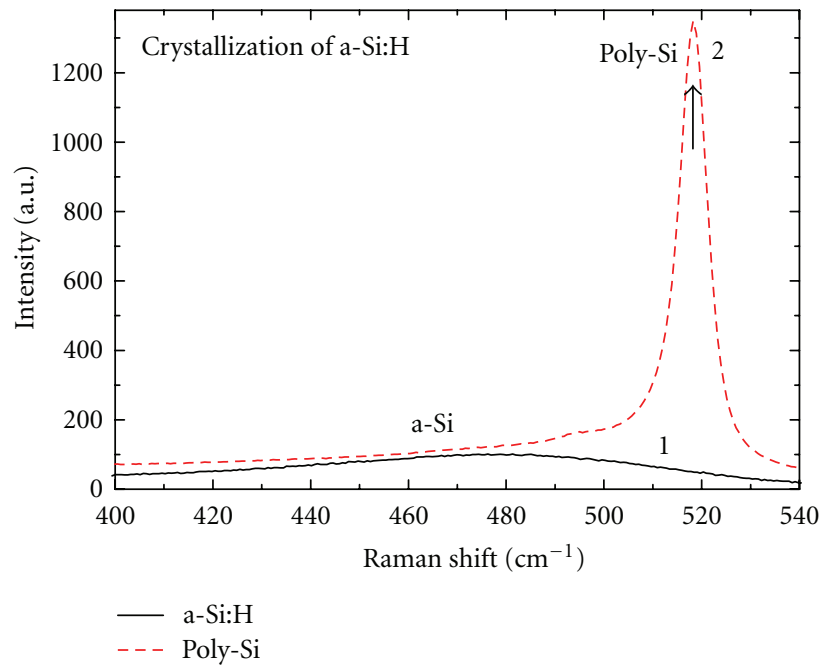

Figure 6: Raman spectra of as-deposited a-Si:H film and crystallized by laser pulse annealing film in frequency range of valence vibration of $\mathrm{Si}-\mathrm{H}$ bonds.

$200^{\circ} \mathrm{C}$ contain mostly $\mathrm{Si}-\mathrm{H}$ bonds. It should be noted that frequencies of stretch vibrations of $\mathrm{Si}-\mathrm{H}$ bonds in silicon nitride and in a-Si: $\mathrm{H}$ are notably different: about $2200 \mathrm{~cm}^{-1}$ for the first case and $2000-2100 \mathrm{~cm}^{-1}$ for the second case. As it was shown by Hien et al. [20], the frequency of stretch vibrations of $\mathrm{Si}-\mathrm{H}$ bonds in the case of neighbouring $\mathrm{N}$ and $\mathrm{H}$ atoms can reach $2122 \mathrm{~cm}^{-1}$. In the case of only $\mathrm{Si}$ neighbouring atoms this frequency is $2012 \mathrm{~cm}^{-1}$ [20]. FTIR method can be used for quantitative hydrogen measurements [21], but for transmission experiments the substrate should be transparent in IR range.

Figure 6 shows the Raman spectra of as-deposited aSi:H film and nanosecond-pulse-annealed film. The Raman spectrum of amorphous silicon contains broad peaks at approximately $480 \mathrm{~cm}^{-1}$ appearing as a result of effective density of trafnsverse optical (TO) vibration modes [19]. Due to scattering on optical phonon modes localized in the nanocrystals, the Raman spectrum of nanocrystals is characterized by narrow peak at position between 500 and $520 \mathrm{~cm}^{-1}$. The position and the width of the peak strongly depend on size and structure of the nanocrystals according to dispersion of the localized modes [22]. The peak width is mainly determined by size dispersion of the nanocrystals. The intensity of the "nanocrystal" peak depends on the volume of nanocrystal phase. So, one can determine the 
volume part of nanocrystal phase: $V_{\text {nano-Si }} / V_{\text {full }}=I_{\mathrm{NC}} /\left(I_{\mathrm{NC}}+\right.$ $\sigma I_{A}$ ), where $I_{\mathrm{NC}}$ and $I_{A}$ are integral intensities of crystalline and amorphous peaks and $\sigma$ is relation between the integral Raman cross-sections of nanocrystal Si and a-Si. According to the literature data, $\sigma$ can change from 0.1 for large grain polycrystalline silicon up to 1.1 for nanocrystalline $\mathrm{Si}$ [23]. As one can see, the used nanosecond treatment leads to almost total crystallization of as-deposited film. According to peak position, the size of nanocrystals in our case should be about $10 \mathrm{~nm}$ [22]. It should be noted that no $\mathrm{Si}-\mathrm{H}$ peaks were detected in nanosecond-pulse-annealed film. So, the pulse annealing can be used not only for crystallization but also for dehydrogenization.

\section{Conclusion}

In conclusion, the FTIR method was applied for determination of concentrations of chemical species in silicon-rich nitride films containing amorphous silicon nanoclusters. It was observed that nearly stoichiometric hydrogenated silicon nitride film contains hydrogen mainly in the form of the $\mathrm{Si}-\mathrm{H}$ bonds even after 5 hours of annealing at temperature $1130^{\circ} \mathrm{C}$. According to Raman spectroscopy data, nanosecond pulse laser treatment leads to crystallization and dehydrogenization of a-Si:H films with initial concentration of hydrogen up to $35 \%$.

\section{Acknowledgments}

The authors are thankful to Dr. A. A. Popov (Yaroslavl Department of FTI RAS) and A. Kh. Antonenko for providing of as-deposited films, Professor A. Misiuk for furnace annealing, and Dr. S. A. Kochubei for help in laser annealing. They are pleased to thank directorate of Scientific and Educational Center "Nanosystems and Advanced Materials," Novosibirsk State University.

\section{References}

[1] N. M. Park, C. J. Choi, T. Y. Seong, and S. J. Park, “Quantum confinement in amorphous silicon quantum dots embedded in silicon nitride," Physical Review Letters, vol. 86, no. 7, pp. 1355-1357, 2001.

[2] M. Dai, K. Chen, X. Huang et al., "Formation and charging effect of $\mathrm{Si}$ nanocrystals in a-SiN $\mathrm{x} / \mathrm{a}-\mathrm{Si} / \mathrm{a}-\mathrm{SiN}_{\mathrm{x}}$ structures," Journal of Applied Physics, vol. 95, no. 2, pp. 640-645, 2004.

[3] C. W. Jiang and M. A. Green, "Silicon quantum dot superlattices: modeling of energy bands, densities of states, and mobilities for silicon tandem solar cell applications," Journal of Applied Physics, vol. 99, no. 11, Article ID 114902, pp. 1-7, 2006.

[4] A. J. Nozik, "Quantum dot solar cells," Physica E, vol. 14, no. 1-2, pp. 115-120, 2002.

[5] C. Doughty, D. C. Knick, J. B. Bailey, and J. E. Spencer, "Silicon nitride films deposited at substrate temperatures $<100^{\circ} \mathrm{C}$ in a permanent magnet electron cyclotron resonance plasma," Journal of Vacuum Science and Technology A, vol. 17, no. 5, pp. 2612-2618, 1999.

[6] T. T. Korchagina, D. V. Marin, V. A. Volodin, A. A. Popov, and M. Vergnat, "Structure and optical properties of SiNx : H films with Si nanoclusters produced by low-frequency plasma- enhanced chemical vapor deposition," Semiconductors, vol. 43, no. 11, pp. 1514-1519, 2009.

[7] J. D. Joannopoulos and G. Lucovsky, The Physics of Hydrogenated Amorphous Silicon, vol. I, Springer, Berlin, Germany, 1984.

[8] A. Milekhin, M. Friedrich, K. Hiller, M. Wiemer, T. Gessner, and D. R. T. Zahn, "Characterization of low-temperature wafer bonding by infrared spectroscopy," Journal of Vacuum Science and Technology B, vol. 18, no. 3, pp. 1392-1396, 2000.

[9] S. Ali, M. Gharghi, S. Sivoththaman, and K. Zeaiter, "Properties and characterization of low-temperature amorphous PECVD silicon nitride films for solar cell passivation," Journal of Materials Science, vol. 40, no. 6, pp. 1469-1473, 2005.

[10] V. I. Belyi, L. L. Vasilyeva, A. S. Ginkover et al., Silicon Nitride in Electronics, Elsevier, New York, NY, USA, 1988.

[11] W. A. Lanford and M. J. Rand, "The hydrogen content of plasma-deposited silicon nitride," Journal of Applied Physics, vol. 49, no. 4, pp. 2473-2477, 1978.

[12] H. J. Stein and H. A. R. Wegener, "Chemically bound hydrogen in $\mathrm{CVD} \mathrm{Si}_{3} \mathrm{~N}_{4}$ : dependence on $\mathrm{NH} / \mathrm{SiH}$ ratio and on annealing," Journal of the Electrochemical Society, vol. 124, no. 6, pp. 908-912, 1977.

[13] V. A. Gritsenko, "Atomic structure of the amorphous nonstoichiometric silicon oxides and nitrides," Physics-Uspekhi, vol. 51, no. 7, pp. 699-711, 2008.

[14] D. V. Tsu, G. Lucovsky, and M. J. Mantini, "Local atomic structure in thin films of silicon nitride and silicon diimide produced by remote plasma-enhanced chemical-vapor deposition," Physical Review B, vol. 33, no. 10, pp. 7069-7081, 1986.

[15] Y. N. Volgin and Y. I. Ukhanov, "Vibration spectra of silicon nitride," Optics and Spectroscopy, vol. 38, pp. 412-415, 1975.

[16] N. Wada, S. A. Solin, J. Wong, and S. Prochazka, "Raman and IR absorption spectroscopic studies on $\alpha, \beta$, and amorphous $\mathrm{Si}_{3} \mathrm{~N}_{4}$," Journal of Non-Crystalline Solids, vol. 43, no. 1, pp. 7$11,1981$.

[17] M. Molinari, H. Rinnert, and M. Vergnat, "Evolution with the annealing treatments of the photoluminescence mechanisms in a-SiN $\mathrm{x}_{\mathrm{x}}: \mathrm{H}$ alloys prepared by reactive evaporation," Journal of Applied Physics, vol. 101, no. 12, Article ID 123532, pp. 1-8, 2007.

[18] G. Scardera, T. Puzzer, G. Conibeer, and M. A. Green, "Fourier transform infrared spectroscopy of annealed siliconrich silicon nitride thin films," Journal of Applied Physics, vol. 104, no. 10, Article ID 104310, pp. 1-5, 2008.

[19] M. H. Brodsky, M. Cardona, and J. J. Cuomo, "Infrared and Raman spectra of the silicon-hydrogen bonds in amorphous silicon prepared by glow discharge and sputtering," Physical Review B, vol. 16, no. 8, pp. 3556-3571, 1977.

[20] T. T. T. Hien, C. Ishizaki, and K. Ishizaki, " $\mathrm{SiH}_{\mathrm{x}}$ absorbance bands in $\mathrm{Si}_{3} \mathrm{~N}_{4}$ powder surfaces analyzed by diffuse reflectance infrared fourier transform spectroscopy," Journal of the Ceramic Society of Japan, vol. 112, no. 1301, pp. 1-5, 2004.

[21] D. M. Goldie and S. K. Persheyev, "Quantitative hydrogen measurements in PECVD and HWCVD a-Si : H using FTIR spectroscopy," Journal of Materials Science, vol. 41, no. 16, pp. 5287-5291, 2006.

[22] V. Paillard, P. Puech, M. A. Laguna, R. Carles, B. Kohn, and F. Huisken, "Improved one-phonon confinement model for an accurate size determination of silicon nanocrystals," Journal of Applied Physics, vol. 86, no. 4, pp. 1921-1925, 1999.

[23] E. Bustarret, M. A. Hachicha, and M. Brunel, "Experimental determination of the nanocrystalline volume fraction in silicon thin films from Raman spectroscopy," Applied Physics Letters, vol. 52, no. 20, pp. 1675-1677, 1988. 


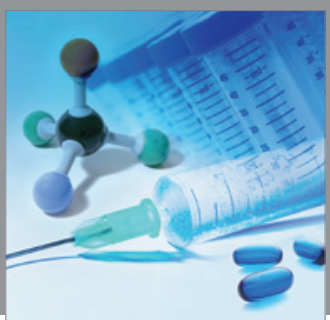

International Journal of

Medicinal Chemistry

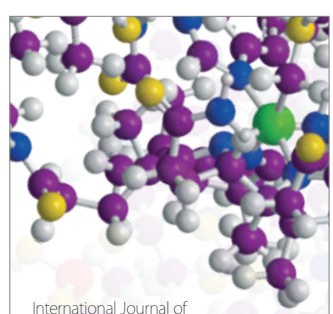

Carbohydrate Chemistry

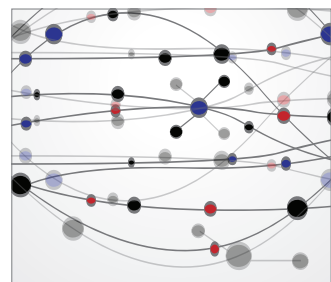

The Scientific World Journal
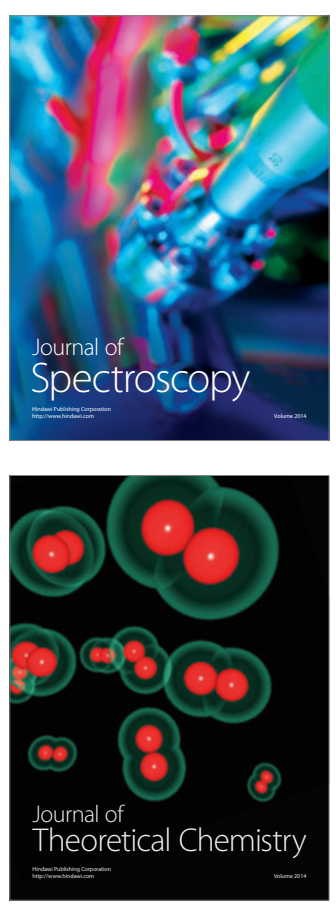
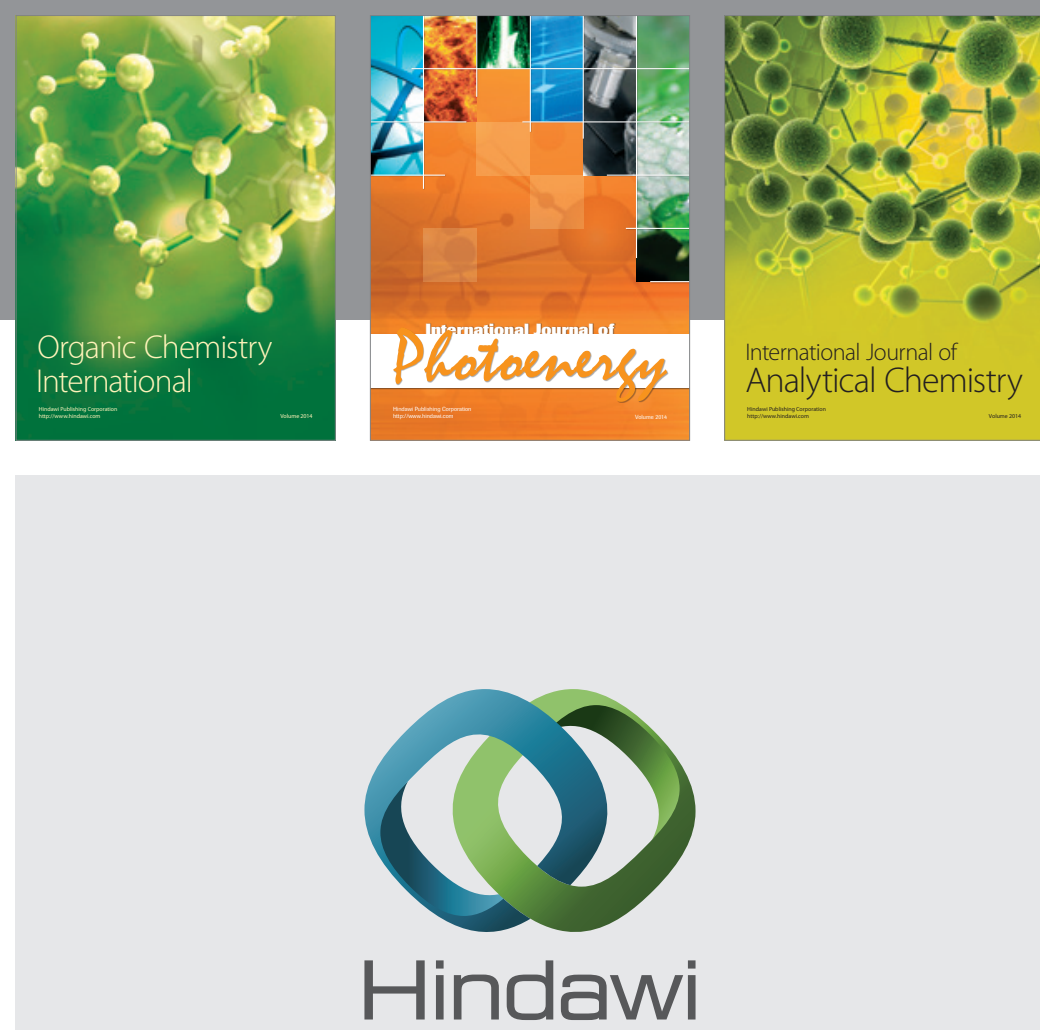

Submit your manuscripts at

http://www.hindawi.com
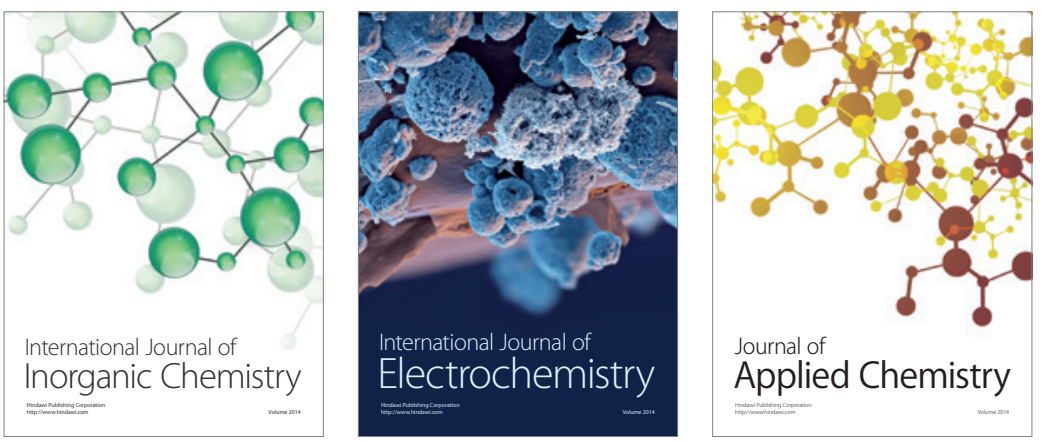

Journal of

Applied Chemistry
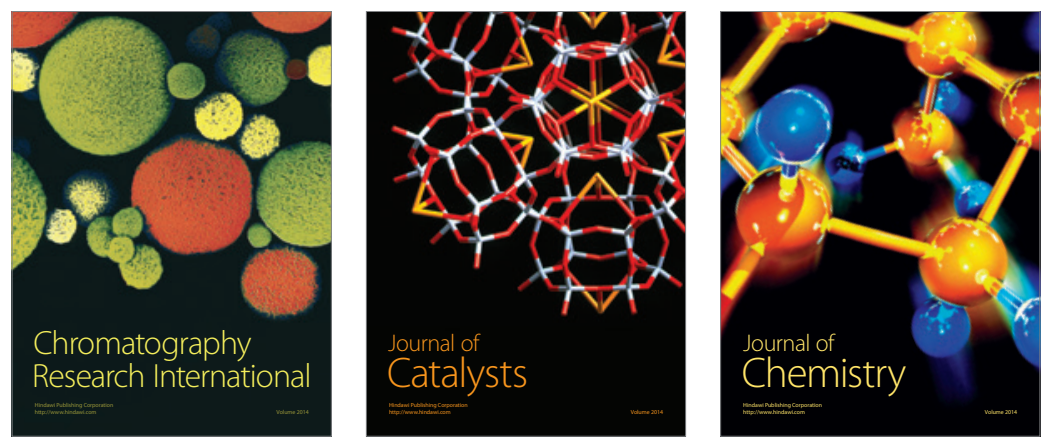
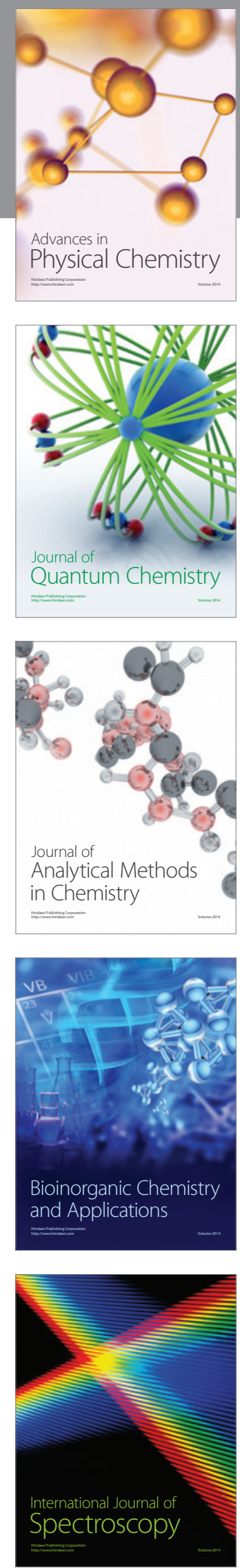